\title{
The in vitro growth and maturation of follicles
}

\author{
H M Picton, S E Harris, W Muruvi and E L Chambers \\ Reproduction and Early Development Research Group, The Light Laboratories, Leeds Institute of Genetics, Health and \\ Therapeutics, University of Leeds, Clarendon Way, Leeds LS2 9JT, UK \\ Correspondence should be addressed to H M Picton; Email: h.m.picton@leeds.ac.uk
}

\begin{abstract}
The development of technologies to grow oocytes from the most abundant primordial follicles to maturity in vitro holds many attractions for clinical practice, animal production technology and research. The production of fertile oocytes and live offspring has been achieved in mice following the long-term culture of oocytes in primordial follicles from both fresh and cryopreserved ovarian tissue. In contrast, in non-rodent species advances in follicle culture are centred on the growth of isolated preantral follicles. As a functional unit, mammalian preantral follicles are well-suited to culture but primordial and primary follicles do not grow well after isolation from the ovarian stroma. The current challenges for follicle culture are numerous and include: optimisation of culture media and the tailoring of culture environments to match the physiological needs of the cell in vivo; the maintenance of cell-cell communication and signalling during culture; and the evaluation of the epigenetic status, genetic health and fertility of in vitro derived mature oocytes. In large animals and humans, the complete in vitro growth and maturation of oocytes is only likely to be achieved following the development of a multistage strategy that closely mimics the ovary in vivo. In this approach, primordial follicle growth will be initiated in situ by the culture of ovarian cortex. Isolated preantral follicles will then be grown to antral stages before steroidogenic function is induced in the somatic cells. Finally, cytoplasmic and nuclear maturation will be induced in the in vitro derived oocytes with the production of fertile metaphase II gametes. Reproduction (2008) 136 703-715
\end{abstract}

\section{Introduction}

The development of technologies to grow and mature oocytes from the most abundant primordial follicles hold many attractions for assisted conception, in humans and in animal production technology. The relatively small size, undifferentiated status and large numbers of primordial follicles present in mammalian ovaries make them prime candidates for use in association with ovarian cryopreservation for the preservation of endangered species and the genetic manipulation of domestic species. The combined technologies of ovarian tissue cryopreservation and in vitro growth (IVG) and in vitro maturation (IVM) of oocytes could therefore be used to help young patients to preserve their fertility through the storage of their own germ cells before abdominal surgery or aggressive chemo- and/or radiotherapy partially or completely destroys their follicular reserve (Picton et al. 2000). Finally, the development of whole follicle culture systems can be used as a research tool to investigate the biology and toxicology of oogenesis in both animals and humans. Research in rodents has provided proof of the potential value of follicle culture as a source of fertile oocytes; however, the advances made using murine IVG/IVM systems have proved difficult to replicate in large animals and humans. In these species, the normal follicular growth span from the primordial to
Graafian follicle stages is very protracted and the changes in the trophic requirements of the cells and their cellular interactions as well as the sheer increase in bulk as the follicular antrum forms present major challenges to follicle culture practitioners. This review will therefore provide insight into the biological landmarks that occur during oocyte and follicle growth in vivo and apply this knowledge to the development of strategies for the IVG and maturation of oocytes in animals and humans.

\section{Overview of follicle and oocyte development in vivo}

In all mammalian species, follicle and oocyte development follow a characteristic sequence of events that commences with the establishment of the ovary shortly after conception and terminates with the ovulation of a fertile, metaphase II oocyte. Throughout the lengthy preantral phase of mammalian folliculogenesis, the development of the oocyte is dependent on, and is concurrent with that of the follicular granulosa cell (GC) layers (Diaz et al. 2007). Effective communication between the different follicular cell types is achieved via homologous and heterologous gap junctional contacts (Picton et al. 2007). Indeed, the cross talk between the somatic GCs and the oocyte is vital to sustain oocyte growth because the major 
source of nutrients for the gamete is the somatic compartment (Harris \& Picton 2007). During follicle growth, oocyte volume and diameter increases as a result of the accumulation of water, ions, carbohydrates and lipids (Fair et al. 1997) such that, in mice for example, there is a 150 fold increase in oocyte volume between primordial and preovulatory oocytes (Pan et al. 2005). The morphological changes and developmental time frames associated with follicle and oocyte development are well characterised across the species (Peters et al. 1975, Gougeon 1996, McNatty et al. 1999) and antral cavity formation commonly occurs when follicular diameters of between $180-250 \mu \mathrm{m}$ are reached. By this stage, the majority of oocyte growth has been completed. In contrast, species specific differences have been recorded in a number of parameters including: i) the overall timeframe for completion of folliculogenesis and oogenesis; ii) the size of the ovulatory follicles and mature oocytes; and iii) differences in the nature, concentrations and effects of the putative growth factors that moderate follicle and oocyte production in vivo. These differences are highly relevant when developing systems that support the complete IVG and IVM of follicles and oocytes.

Recent research has revealed that oocyte secreted factors regulate the initiation of primordial follicle growth (see Picton 2001 for review) and moderate the known trophic actions of the gonadotrophins $\mathrm{FSH}$ and $\mathrm{LH}$ on preantral and antral follicle growth (Knight \& Glister 2006, McNatty et al. 2007, Webb \& Campbell 2007). A plethora of putative regulators of folliculogenesis in vivo have been identified, some examples of these factors are shown in Fig. 1. The tyrosine kinase receptor Kit and the two different isoforms of its ligand, kit ligand (KL), have been localised to oocytes and GCs and have been shown to promote oocyte growth and maintenance of meiotic arrest in response to FSH receptor (FSHR) levels. While low concentrations of FSH promote oocyte growth by increasing KL-2 expression and by reducing the ratio of $K L-1 / K L-2$, high concentrations of FSH enhance follicle development but impair oocyte growth (Thomas \& Vanderhyden 2007). Other regulators of follicle growth include epidermal growth factor (EGF; Qu et al. 2000) and its receptor; activin (Hulshof et al. 1997, Telfer et al. 2008); basic fibroblastic growth factor (bFGF; Shikone et al. 1992); members of the insulin like growth factor (IGF) family and their binding proteins (Thomas et al. 2007), transforming growth factor- $\beta$ (TGFB) superfamily members (Knight \& Glister 2006) including somatic derived anti-Müllerian hormone $(\mathrm{AMH})$, oocyte derived growth differentiation factor-9 (GDF9; McGrath et al. 1995, Dong et al. 1996); and the bone morphogenetic proteins (BMPs) especially BMP4, BMP7 and BMP15 (Shimasaki et al. 1999, Otsuka et al. 2001). Other factors such as retinoblastoma protein (RB1) may also be important (Bukovsky et al. 1995). Changes in follicle morphology and cell number, together with the stage specific follicular responsiveness to the growth factors detailed here and the development of steroidogenic capacity can be used as functional markers to confirm the normality of follicle development in vitro.

Oocyte developmental competence is progressively acquired following a coordinated series of structural and functional changes in the gamete and surrounding cumulus cells. However, it is not until the final days of follicular development that oocytes acquire the capacity to undergo meiotic progression to metaphase II. The redistribution of the cortical granules and changes in mitochondrial number, activity and distribution occur during the terminal stages of oocyte maturation in vivo

Preantral follicle growth rates in different species in vivo

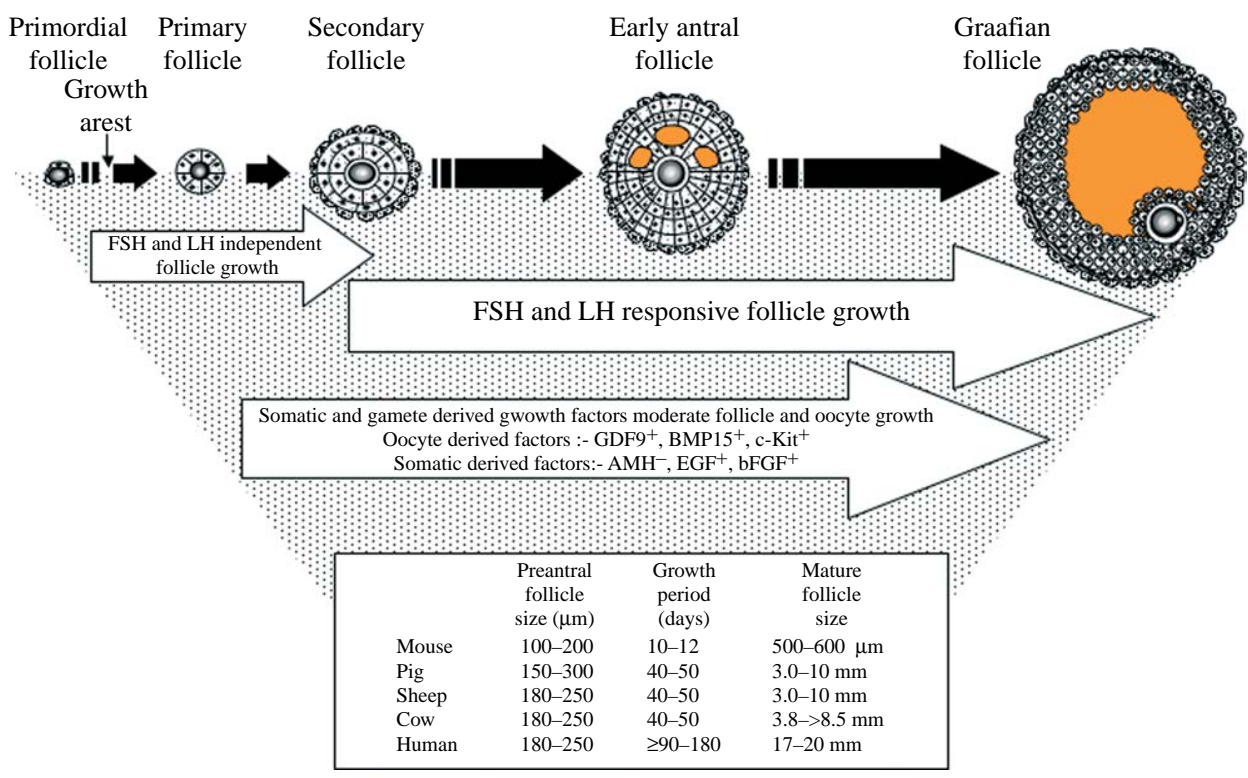

Figure 1 Diagrammatic representation of the regulators and developmental time frames of mammalian follicle and oocyte development in vivo. Examples of key growth regulators of somatic and oocyte origin are shown. Follicle sizes and growth rates are approximations for each species. + indicates putative growth stimulators; - indicates growth inhibitors; all abbreviations are defined in the text. The figures were collated from data published in a number of different sources as detailed in the text including Gosden \& Telfer (1987), Gougeon (1996), McNatty et al. (1999, 2007), Van den Hurk et al. (2000) and Thomas et al. (2003). 
(Wilding et al. 2001, Van Blerkom et al. 2002). Cytoplasmic and nuclear maturation of the oocyte is further characterised by a cascade of molecular events and check points which include changes in the transcription and translation of RNA, DNA replication and repair, chromosome condensation, spindle formation and development of the mechanisms for sperm head penetration (Swain \& Smith 2007). Oocyte maturation in vivo is triggered by the preovulatory surge of gonadotrophins and particularly by high levels of LH. The LH driven follicular cascade results in a shift in steroid production by GCs from predominately oestrogen to a progesterogenic environment and a decrease in intracellular CAMP in the oocyte, which is induced at least in part by the loss of junctional contacts between the cumulus cells and oocyte (Mehlmann 2005, Sela-Abramovich et al. 2006). Activation of the molecular pathways leading to the production of hyaluronic acid by the cumulus cells occurs in response to the $\mathrm{LH}$ surge leads to the mucification and expansion of the cumulus (Schoenfelder \& Einspanier 2003). The loss of junctional contacts between the oocyte and somatic cells in turn triggers the resumption of meiosis in mature oocytes as it further reduces CAMP concentrations (Vaccari et al. 2008), leads to deactivation of cAMP dependent protein kinase $\mathrm{A}$ and reduces the inhibitory influences of purines on the maintenance of meiotic arrest (Swain \& Smith 2007). All the molecular and cellular events which occur during oocyte maturation in vivo must be mimicked in vitro to produce fertile gametes.

\section{Follicle and oocyte growth and development in vitro}

The avascular follicular unit is relatively well-suited to culture environments. With the exception of oocytes from antral follicles that typically only need a short period of manipulation and maturation in culture, oocytes from small antral follicles and all preantral stages of follicle development require extended periods of growth in vitro to acquire developmental competence. It is vital therefore, that a detailed knowledge of biology of follicle and oocyte development in vivo is used to inform the development of strategies for the growth of follicles and oocytes in vitro. The success of IVG and IVM systems will be influenced by the nature of the tissue, the culture environment and the choice of endpoint(s) selected. The latter can be the production of antral or Graafian follicles, metaphase II oocytes, cleavage stage embryos or blastocysts (Fig. 2).

\section{The follicle culture environment in vitro}

A number of different culture systems have been developed to grow follicles from different species. There is some commonality among these systems but there are also many species-specific differences. In all IVG protocols, it is vital to optimise: i) the supply of nutrients, electrolytes, antioxidants, amino acids, energy substrates, vitamins

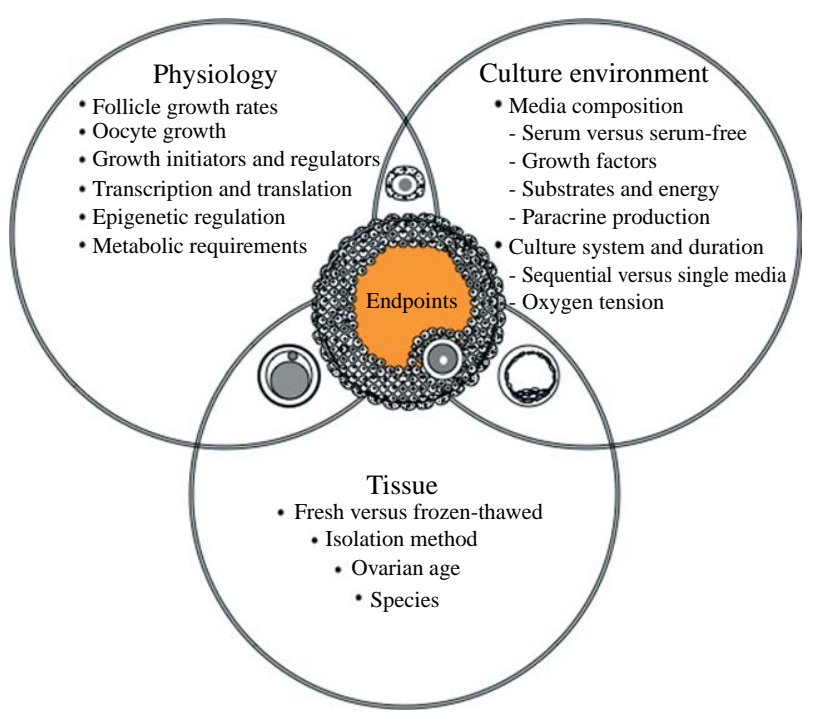

Figure 2 Summary of the critical determinants of the success of in vitro growth and maturation systems for mammalian oocytes. The success of the culture strategy will be influenced by the endpoint selected. These end points can be the production of antral or Graafian follicles, metaphase II oocytes, cleavage stage embryos or blastocysts.

and growth factors as these components of the culture environment are essential to sustain viability and growth; and ii) the removal of all waste products such as ammonia that may accumulate, as these waste secretions may be detrimental to growth. A variety of base media have been used for IVG of follicles from different species, these include: minimum essential medium (Eppig \& Schroeder 1989, Spears et al. 1994, Cortvrindt et al. 1996, Jewgenow 1998, Newton et al. 1999, Picton et al. 1999b); Waymouth medium (Eppig \& O'Brien 1996, Muruvi et al. 2005); and McCoy's 5a medium (Telfer et al. 2008). The base media used for follicle culture is supplemented with different culture additives including: antibiotics/antimycotics; commercial preparations of insulin, transferrin and selenium (Wright et al. 1999); physiologically relevant levels of insulin, IGF1 and IGF2 (Newton et al. 1999, Picton et al. 1999b, Louhio et al. 2000); GDF9 (Hreinsson et al. 2002); activin (Telfer et al. 2008); and 8-bromo cAMP and guanosine monophosphate as apoptosis inhibitors (Scott et al. 2004b, Zhang et al. 2004). The efficacy of these additives in supporting follicle growth and survival depends on the culture system itself, the presence or absence of other factors including serum, growth factor concentration and the duration of exposure.

An important consideration when developing a culture medium for the IVG and maturation of follicles is the type and concentration of energy substrate included in the base medium. Basic research has shown that glucose is a common energy source for almost all types of animal cells; however, over the last few decades, it has become clear that mature oocytes of many mammalian species, including mice (Biggers et al. 1967, Leese \& Barton 1984, Harris et al. 2007, 2008), cows (Gandolfi et al. 1998) 
and humans (Roberts et al. 2002, Harris \& Picton 2007) preferentially metabolise pyruvate and have little capacity for the metabolism of glucose. Laboratory research has also shown that mouse oocytes have a high capacity for the consumption of pyruvate and oxygen at all stages of follicle development (Harris et al. 2008) while glucose consumption is below detection levels (Biggers et al. 1967, Eppig 1976, Harris et al. 2007). As a consequence of this evidence, glucose would be preferentially utilised by the somatic cells as the primary energy substrate in IVG media supporting follicle growth, whereas IVM media should be supplemented with pyruvate to support the energy needs of the maturing oocyte.

The inclusion of serum from homologous or heterologous sources in IVG and IVM media has ignited considerable debate. Serum contains proteins, amino acids, carbohydrates, trace elements, hormones, growth factors and extracellular matrix components which promote cell adhesion and proliferation. Extracellular matrix has been shown to moderate follicle survival in organ culture (Hovatta et al. 1999, Scott et al. 2004a). Serum acts as a source of albumin, which balances the osmolality and scavenges potentially harmful molecules and metal ions that can act as a source of free oxygen radicals. Serum also acts as a source of precursors for steroid biosynthesis (Hulshof et al. 1995). However, the inclusion of serum frequently blunts the response of proliferating cells to physiological doses of growth factors and it can act as a source of transmissible pathogens and viruses such as hepatitis $B$ and $C$ and bovine viral diarrhoea virus. Finally, the addition of serum in long-term cultures has been shown to lead to epigenetic modifications and foetal overgrowth syndromes (for example see Young et al. 1998, van Wagtendonk-de Leeuw et al. 2000). If serum is omitted from culture media, it is necessary to supplement the media with purified serum albumen or synthetic serum substitutes as a carrier molecule. Comparisons of the efficacy of IVG serum-based versus serum-free culture systems have been conducted in mice. Eppig et al. (1998) compared oocyte-GC complex development in culture medium supplemented with either foetal calf serum (FCS) or bovine serum albumin (BSA). More oocytes cultured with FCS cleaved after fertilisation and were competent to develop to the blastocyst stage than those cultured in BSA alone. In contrast, we and other authors have shown that FCS increased oocyte extrusion and follicle degeneration in isolated ovine follicles (for example Newton etal. 1999). Similarly, the replacement of FCS with BSA increased the percentage of morphologically intact preantral cat follicles by up to $30 \%$ (Jewgenow 1998).

There is a clear need to optimise the $\mathrm{pH}$, temperature and oxygen tension of the culture environment in order to maximise the potential of in vitro derived oocytes (Ye et al. 2007). For example, although murine ovarian tissue is exposed to plasma oxygen levels of about $5 \%$ in vivo, mouse follicles grown in vitro in 5\% oxygen had a higher frequency of mature oocytes with incorrectly aligned chromosomes and many died prematurely when compared with follicles cultured in $20 \%$ oxygen ( $\mathrm{Hu}$ et al. 2001). Similarly, sheep follicles grown in 5\% oxygen had reduced antral cavity formation and increased lactate and glucose consumption when grown under hypoxic conditions of $5 \%$ oxygen relative to sized matched counterparts that were grown in $20 \%$ oxygen (Jin et al. 2007). Additionally, the temperature of the media used for tissue transportation and holding prior to follicle harvest must be optimised to minimise apoptosis (Schmidt et al. 2003, Lucci et al. 2004).

Follicle culture practitioners need to consider the direct effects of long-term culture and sub-optimal culture environments on the epigenetic information and methylation status of key imprinted genes in oocytes (Huntriss \& Picton 2008). This issue is of particular relevance to IVG and maturation strategies as epigenetic information that is essential for normal development is acquired during gametogenesis and a growing body of evidence suggests that assisted reproductive technologies, and especially those involving extended culture and invasive micromanipulations may affect these complex processes and lead to disorders of genomic imprinting (Huntriss \& Picton 2008). Imprinted genes including the maternally expressed H19 gene, IGF2 and also epigenetic regulators such as members of the DNA methyltransferases family DNMT1 and DNMT3A have been shown to be aberrantly expressed following assisted reproduction technologies (FernandezGonzalez etal.2004, Sagirkaya etal.2007). Analysis of the DNA methylation status of differentially methylated regions of the imprinted genes $H 19$, paternally expressed gene $1 /$ mesoderm-specific transcript (Peg1/Mest) and lgf $2 r$ in fully grown murine, germinal vesicle- staged oocytes derived in vitro from preantral follicles compared with in vivo grown counterparts indicated a loss of methylation at the Igf2 $r$ and Mest/Peg1 loci, as well as a gain of methylation of H19 (Kerjean et al. 2003). Furthermore, demethylation of the Peg1/Mest gene differentially methylated region has been observed in murine oocytes after extended culture (Imamura et al. 2005) suggesting that maternal imprints may be susceptible to demethylation during follicle culture. Further confirmation of this observation is provided following the detection of abnormal hypermethylation at the $\mathrm{H} 19$ locus in human oocytes matured in vitro (Borghol et al. 2006). Culture induced epigenetics disruption has been associated with the additions to FCS to different media (Khosla et al. 2001, Fernandez-Gonzalez et al. 2004). Although the exact mechanisms of imprinting disruption following extended culture are unclear, it is likely that cellular stress induced by suboptimal culture environments is highly relevant with the latter being manifest by the accumulation of $\mathrm{NH}_{3}$ in spent culture media (Lane \& Gardner 2003). It is, however, important to note that there is a high degree of discordance between the imprinting status of genes in humans and other species (Morison et al. 2005) and there is variation in the regulation of epigenetic information including DNA 
methylation during preimplantation development between mammalian species (Beaujean et al. 2004, Fulka et al. 2004, Vassena et al. 2005). Consequently, it is vital that epigenetic health checks are conducted on all oocytes derived following IVG and IVM before these tissues can be used in a clinical setting.

\section{Methods for harvesting follicles for culture}

Different follicle isolation methods have developed for preantral follicle culture. Follicle yield is dependent on the species of interest and on the reproductive age of the ovarian tissue as follicles are more numerous and the isolation method tends to be easier in neonatal and prepubertal ovaries than in adult ovaries (Figueiredo et al. 1993, Carámbula et al. 1999). Mechanical isolation methods using fine gauge needles or forceps have been used to isolate follicles from mice (Boland et al. 1993, Spears et al. 1994, Cortvrindt et al. 1996), rats (Zhao et al. 2000), pigs (Wu et al. 2001), cattle (Figueiredo et al. 1994, Gutierrez et al. 2000), sheep (Cecconi et al. 1999) and humans. Some workers have advocated combining ovarian dissociation methods such as grating or mincing with sieving methods (Jewgenow 1998). Follicles have also been successfully dissected out of thin slices of cortex that has been prepared using a skin-grafting knife and/or small scalpel blades (Guttierrez et al. 2000, Picton et al. 2003). The main advantage of these mechanical isolation methods is that they recover intact follicles surrounded by both a basement membrane and theca cell layer(s). However, all of these techniques are slow and labour intensive, and typically they only permit the recovery of a small number of follicles (Telfer et al. 2000). To combat these technical problems many researchers routinely used enzymes to aid follicle recovery. Enzymatic follicle isolation typically involves incubating tissue in collagenase and/or DNAse (for example Eppig \& Schroeder 1989, Eppig \& O'Brien 1996, Newton et al. 1999) to soften and disaggregate the tissue matrix, followed by detachment of the follicles from stromal tissue using needles. The most common adverse consequence of enzymatic isolation of follicles is that the basement membrane is degraded and the theca cell layer(s) are removed (Nayudu et al. 2001). Although, this damage can be minimised by limiting enzyme exposure (Shuttleworth et al. 2002), the destruction of the basement membrane and theca layers can result in the spontaneous migration of GCs away from the oocyte, once the follicles are placed into culture.

\section{Culture systems for the IVG and maturation of mammalian follicles and oocytes}

A series of culture systems have been developed to support the IVG and maturation of follicles and oocytes from a range of different species. Each system is tailored to the stage of follicle development of interest.

\section{Primordial and primary follicle culture}

To maximise the reproductive potential of fresh and cryopreserved ovarian tissue it is necessary to develop culture strategies that support the activation and sustained IVG of primordial follicles as this is the most abundant stage of follicles development present in mammalian ovaries. Initial attempts at primordial follicle growth in vitro focussed on the growth of isolated follicles. While the data clearly show that it is possible to harvest rodent primordial follicles by mechanical means, in the tougher cortex of large animals and humans primordial follicles have to be isolated using enzymatic methods (Greenwald \& Moor 1989; and human Oktay et al. 1997, Abir et al. 1999, Huntriss et al. 2002, Rice et al. 2008). Consequently, although a high percentage of primordial follicles are viable following extraction ( 71\%: Oktay et al. 1997), and growth can be supported for $24 \mathrm{~h}$ within a collagen gel (Abir et al. 1999), beyond this time follicles rapidly lose their three dimensional structure (Spears et al. 1994, Cortvrindt et al. 1996), the follicles collapse, the pregranulosa cells migrate away from the oocyte and/or oocyte extrusion and degeneration occurs. It is possible that the lack of influence from the extra-follicular cortical cells contributes to the demise of isolated primordial follicles in vitro as the presence of stromal cells around primordial follicles has been shown to improve initial culture success (Osborn et al. 1997). In contrast to the majority of publications, a recent report demonstrated that lectinaggregated, serum-free cultures supported the long-term survival and growth of isolated ovine primordial follicles from both fresh and cryopreserved neonatal lamb ovary ovarian cortex (Muruvi et al. 2005). Oocyte growth and GC differentiation were further enhanced in lectinaggregated cultures following exposure to $\mathrm{KL}$ in vitro and the oocytes reached diameters equivalent to those of oocytes from primary follicles derived in vivo (Muruvi et al. 2005). While these recent results are encouraging, they are by no means definitive as the optimal methodology for primordial follicle growth in vitro.

An alternative approach that has consistently proved successful for primordial follicle culture in a number of species is to grow these early stages in situ within fragments of the ovarian cortex. In early in situ culture experiments, large numbers of oocytes underwent atresia (Blandau et al. 1965), and no follicular growth was observed (Baker \& Neal 1974). However, Eppig \& O'Brien (1996) reported the birth of live pups from oocytes derived from primordial follicles grown in situ following the culture of foetal mouse ovaries. Two subsequent studies have also produced live offspring following the growth of oocytes present within cryopreserved ovaries (Liu et al. 2001) and foetal ovaries obtained at E12.5 (Obata et al. 2002). In situ cultures of primordial and primary follicles can be conducted by culturing fragments of ovarian cortex directly or by 
grafting the cortical fragments beneath the highly vascularised chorioallantoic membrane of chick embryos (Fortune et al. 2000, Cushman et al. 2002, Qureshi et al. 2008). Whichever route is adopted, culture of thin cortical strips: i) avoids the damage caused by the follicle harvesting procedure; ii) minimises the chances of necrosis by maximising the surface area of the tissue for gaseous exchange and fulfilment of the nutrient requirements; and iii) provides a complex support system that more closely resembles the ovary in vivo as the follicles remain both intact and in contact with the surrounding stromal cells, which provide the local biochemical control pathways that trigger the initiation of follicle growth.

In situ cortical cultures have been conducted for a number of species over varying time frames with or without extracellular matrix and high levels of serum (Hovatta et al. 1999, Wright et al. 1999) or in serum-free medium (Picton et al. 1999b, Webber et al. 2007, Telfer et al. 2008). During the in situ culture pieces of ovarian cortex are placed onto a physical support, such as a porous membrane insert, in culture wells and the tissue is then covered with a meniscus of culture media (Devine et al. 2002). Using this approach, follicles may remain viable and are morphologically normal after 1-3 weeks of culture. Using this method, recruitment of primordial follicle growth has been demonstrated in a number of species (cows: Wandji et al. 1996, 1997, Braw-Tal \& Yossefi 1997, Fortune et al. 1998; baboons: Fortune et al. 1998, hamsters: Yu \& Roy 1999, humans: Hovatta et al. 1999, Picton et al. 1999b, Wright et al. 1999). Furthermore, multilayer preantral follicles have been isolated following the culture of fragments of ovarian cortex (Telfer et al. 2008) or after culture of whole mouse ovaries (Eppig \& O'Brien 1996). Despite these successes, not all cortical strip culture systems are equally effective and further optimisation of the oxygen tension and growth additives are required to sustain high levels of primordial and primary follicle growth in vitro.

The problems encountered during the culture of isolated primordial follicles are replicated during primary follicle IVG. However, recent data have shown that it is possible to use an attachment based culture system to drive secondary follicles in vitro from isolated primary follicles harvested from fresh or cryopreserved neonatal lamb ovaries (Muruvi et al. 2008). Here, the oocytes from isolated primary follicles were shown to be able to reassemble functional 'follicle units' in vitro and to support the sustained growth of these reorganised follicles to secondary stages over more than 42 days in vitro. After 7, 11 and 30 days of culture increases in follicle diameter of $7 \mu \mathrm{m}$ (Nuttinck et al. 1993), $19 \mu \mathrm{m}$ (Itoh \& Hoshi 2000) and $35 \mu \mathrm{m}$ (Saha et al. 2000) respectively, have been reported for small bovine follicles. In this cohort of studies, follicle survival and growth depended on the use of feeder layers of somatic cells.

\section{Preantral-antral follicle culture}

Unlike primordial and primary follicle culture, preantral-antral cultures are rarely conduced in situ but rather follicle isolation appears to be crucial for future development in vitro. The growth characteristics of preantral follicles in vitro and the duration of culture are highly dependent on the culture system and the species of interest. Preantral follicles have been cultured with serum on a plastic substratum (Figueiredo et al. 1994, Jewgenow 1998), grown on somatic cell monolayers (Itoh \& Hoshi 2000), or in serum-free environments (Newton et al. 1999, Gutierrez et al. 2000). Preantral follicle culture systems broadly fall into two categories: i) culture systems that allow follicle attachment and loss of follicle integrity as illustrated in Fig. 3 (mouse: Eppig \& Schroeder 1989, Cortvrindt et al. 1996); or ii) three dimensional (3-D) culture systems that maintain follicle integrity. Three dimensional systems have been achieved through the use of physiological serum-free media approaches as shown in Fig. 4 (sheep: Newton et al. 1999; human: Picton et al. 1999b, Telfer et al. 2008), through the use of hydrophobic membranes that prevent attachment (mouse: Nayudu \& Osborn 1992); or via encapsulation in collagen (mouse: Carroll et al. 1991a; pig: Hirao et al. 1994) or alginate gels (Xu et al. 2006, West et al. 2007).

\section{Preantral follicle culture in rodents}

Preantral follicle culture has been pioneered in rodents. The advantage of using rodents is that their ovaries are small and contain a large number of follicles embedded within a soft stromal matrix (Hartshorne 1997). Enzymatic follicle harvest has been used extensively in this species and the problems associated with the loss of follicle integrity following isolation have been addressed by placing granulosa-oocyte complexes onto collagentreated porous membranes or poly-L-lysine coated dishes (Eppig \& Schroeder 1989, Cain et al. 1995). Here, the outer GCs attach to the collagen or lysine, which limits migration away from the oocyte (Eppig 1994). Alternatively, intact follicles can be placed into microdrops of culture media under oil in uncoated dishes. In the latter case, the theca cells migrate onto the surface of the dish to form a monolayer that then anchors the follicle and prevents further GC migration (Nayudu et al. 2001). The latter approach has permitted the successful development of follicles isolated from both fresh (Cortvrindt et al. 1996) and cryopreserved (Smitz \& Cortvrindt 1998, Newton \& Illingworth 2001) murine tissue (see examples in Fig. 3). Recent data have also confirmed that for murine oocytes derived using an attachment IVG system, criteria such as oocyte diameter, chromatin configuration, transcriptional activity, intracytoplasmic calcium signalling and ability to undergo meiosis were similar in the in vitro derived oocytes compared with in vivo grown counterparts (Pesty et al. 2007). 

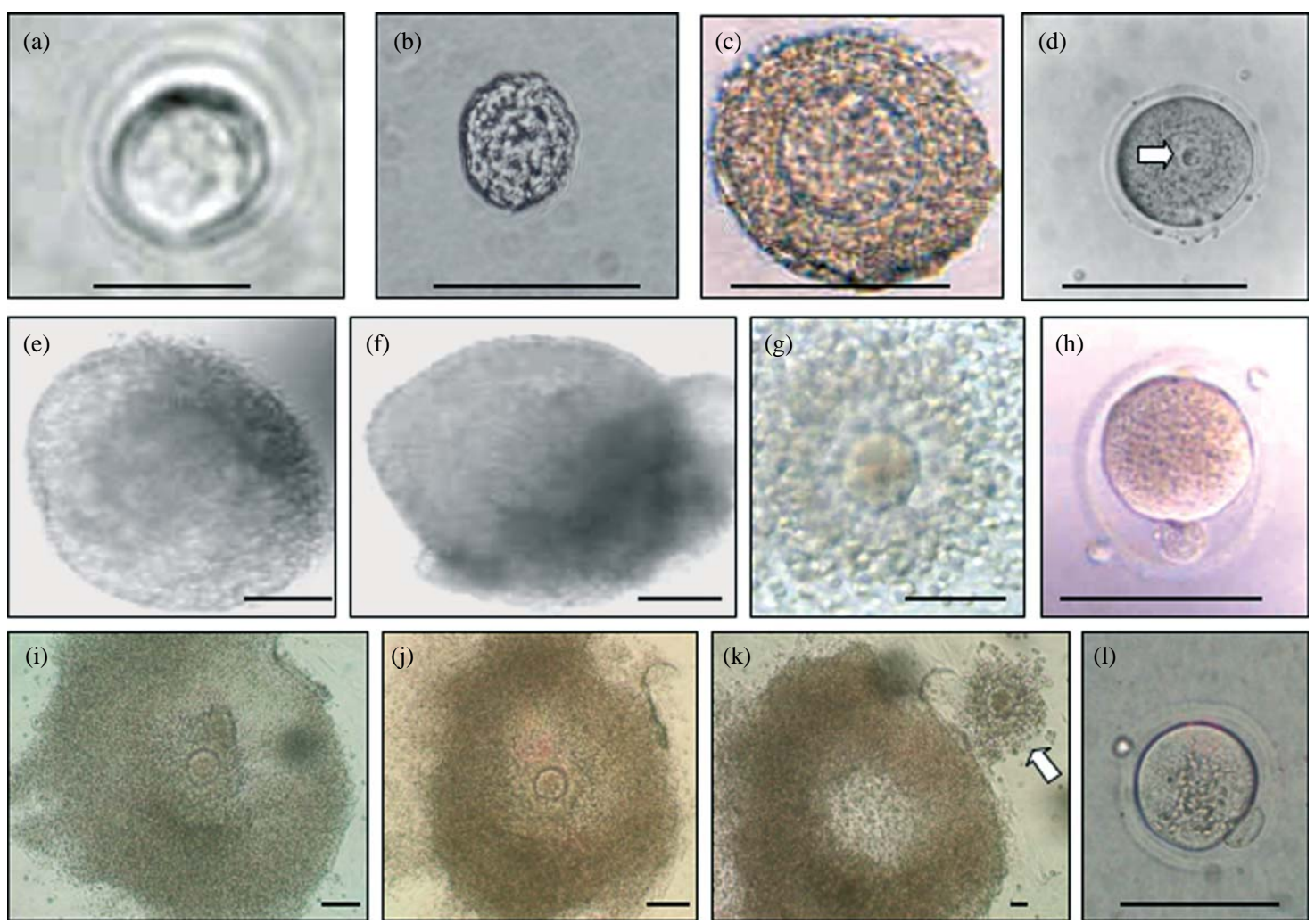

Figure 3 Morphology and growth characteristics in vitro of isolated murine follicles at different stages of development after growth in vitro in an attachment based culture system. Images (a)-(d), and (g)-(h), are of in vivo grown follicles and oocytes for comparison: (a) primordial follicle; (b) primary follicle with 1-2 layers of granulosa cells; (c) secondary follicle with 2-3 layers of granulosa cells and 1 layer of theca cells; (d) immature oocyte from a secondary follicle: the germinal vesicle is visible (arrow); (e) antral follicle; (f) pre-ovulatory follicle; (g) in vivo grown cumulus-oocyte complex; (h) denuded metaphase II oocyte grown and matured in vivo. Images (i)-(I) are of in vitro grown follicles and oocytes derived from the attachment culture system of Cortvrindt et al. (1996): (i) in vitro grown two-dimensional follicle with antral-like cavity; (j) in vitro grown twodimensional pre-ovulatory follicle with antral-like cavity; $(\mathrm{k})$ in vitro grown follicle after ovulation of the cumulus oocyte complex (arrow); (I) denuded metaphase II oocyte derived from a pre-antral follicle grown to maturity in vitro. Scale bars $=100 \mu \mathrm{m}$, except in (a) where bar $=20 \mu \mathrm{m}$. Reproduced from Picton et al. (2004), page 198, Figure 1, with permission from Taylor \& Francis.

Three dimensional IVG systems originated with the culture of murine preantral follicles (for example: Eppig \& Schroeder 1989, Carroll et al. 1991b, Nayudu \& Osborn 1992, Hartshorne et al. 1994, Spears et al. 1994, Cortvrindt et al. 1996). Using this approach, intact follicles are cultured on hydrophobic membranes that inhibit cellular attachment and migration (Nayudu \& Osborn 1992). Alternatively, mouse follicles are cultured in microdrops under mineral oil and grown from mid-preantral sized follicles to the Graafian stage in about 6 days. The daily transfer of follicles to a new culture well prevents follicular attachment (Boland et al. 1993). The antral follicles derived using the threedimensional system have normal morphology and steroid production (Nayudu \& Osborn 1992, Hartshorne et al. 1994, Spears et al. 1994); furthermore, up to $80 \%$ of these follicles 'ovulate' in vitro in response to an exogenous ovulatory stimulus (Rose et al. 1999) and the oocytes are healthy and can be fertilised with the production of live young (Spears et al. 1994).

A number of different approaches for three-dimensional culture have been tested in mice; these methods may be more compatible with the IVG requirements of the larger follicles collected from domestic ruminants and humans. Anchorage independent cultures of whole murine follicles have utilised inverted drop cultures of preantral follicles of 180-240 $\mu \mathrm{m}$ diameter (Wycherley et al. 2004). Rotating wall suspension cultures have also been tried (Rowghani et al. 2004). Alternatively, encapsulation of follicles in inert alginate hydrogels has been shown to be a good option for the sustained growth of larger follicles. Alginate is a linear polysaccharide copolymer of $\beta$-D-mannuronic acid and $\alpha$-L-guluronic acid, which is produced by brown algae (Haug et al. 1967). It is thought that the alginate matrix mimics the stromal microenvironment of the ovary and as such will better support the growth and maturation of multilayered secondary follicles in large animals, primates and humans (Kreeger et al. 2007). Early reports demonstrated that murine follicles grown in alginate capsules reached the sizes typically observed in vivo (Pangas et al. 2003, Kreeger et al. 2007). Extended growth, coordinated differentiation of follicular cell types, antral cavity formation, theca cell differentiation, and oocyte maturation and hormone production were achieved by 

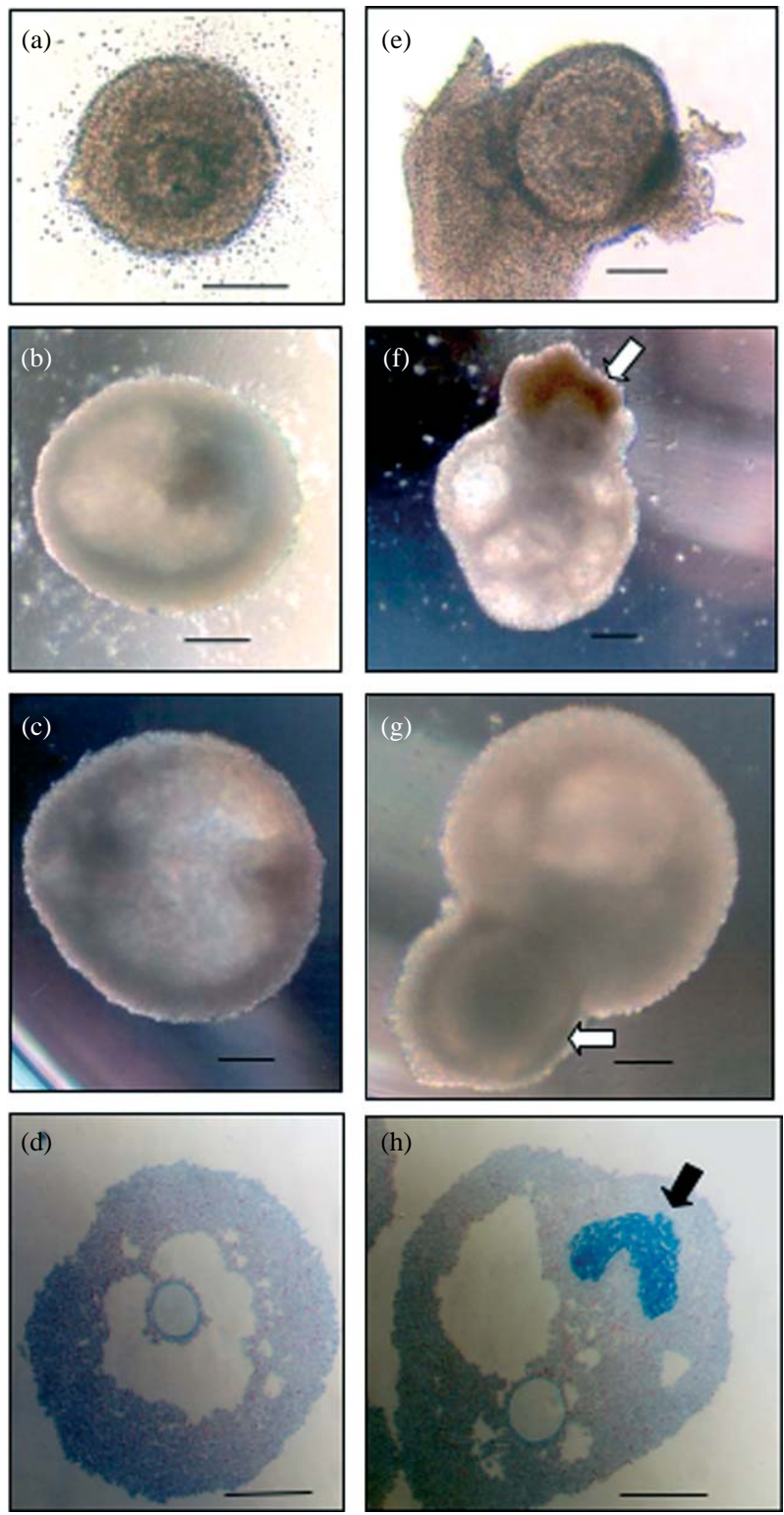

Figure 4 In vitro growth sequence of isolated preantral (180-220 $\mu \mathrm{m}$ diameter) sheep follicles grown for 30 days in serum-free culture media. Theca-free follicles harvested by enzyme digestion (a) develop antral cavities in vitro (b, c) and show no evidence of the presence of the basement membrane at the end of culture as indicated by the lack of blue staining for the presence of collagen (d). In contrast, theca-enclosed follicles collected by mechanical isolation (e) show evidence of antral cavity formation by outgrowth from the dense theca and stromal cells (f, g; arrows) which remain concentrated within one area as indicated by blue staining for collagen (h) after extended culture. Scale bars $=50 \mu \mathrm{m}$. Reproduced from Picton et al. (2003) with permission from Nottingham University Press.

decreasing matrix stiffness and by altering the alginate scaffold concentration (Xu et al. 2006, West et al. 2007). This method of in vitro folliculogenesis from preantral stages has also resulted in the production of live young (Xu et al. 2006). While these data are very encouraging, it is important to note that the follicle and oocyte growth rates in all of these reports are increased over in vivo grown counterparts. The health of oocytes derived from follicles with accelerated growth rates needs to be fully verified before these systems can be considered suitable for the clinical use of in vitro derived oocytes.

Preantral follicle culture in large domestic animals and humans

Despite the many advances in rodent follicle culture detailed above, these achievements have proved difficult to replicate in large animals and humans. One of the main reasons for the lack of progress is that it is technically more difficult to recover follicles from these species, as the cortex has a more dense and fibrous consistency (Telfer 1996) and follicle isolation frequently requires the use of aggressive enzyme-based protocols. Nevertheless, in recent years, it has proved possible to maintain the three-dimensional integrity of ruminant (Newton et al. 1999, Gutierrez et al. 2000, Picton et al. 2003, Thomas et al. 2007) and human follicles (Picton et al. 1999b, Telfer et al. 2008). The philosophy that underpins this system is that cultured GCs form distinct clumps of rounded cells that closely resemble the morphology (Chang et al. 1977) and steroidogenic phentoype of GCs in vivo (Campbell et al. 1996, Picton et al. 1999a) rather than acquiring a fibroblastic character associated with attachment to the plastic culture dish. This species-specific system maintains follicle integrity (Fig. 4) and follicle cells retain their normal ultrastructure (Jin et al. 2004). Antral cavity formation occurs in $50 \%$ of isolated ovine secondary follicles with a start size of $180-220 \mu \mathrm{m}$ after 12-14 days of culture, with growth being supported up to diameters of $1.2 \mathrm{~mm}$ over 30 days in both fresh and cryopreserved tissues (Newton et al. 1999). Using this system, follicle growth rates can be manipulated by the presence/absence of the theca cell layer, as well as the presence/absence of basement membrane components in the culture media. These data support the concept first observed in murine follicles by Boland \& Gosden (1994), that the theca cells have biochemical effects on oocyte growth and development in vitro, which are mediated via the GCs (Kotsuji et al. 1994, Richard \& Sirard 1996). Additionally, on the provision of appropriate concentrations of androgen substrate, sheep follicles grown over 30 days resulted in the biosynthesis of limited, but physiological levels of oestradiol in vitro (Newton et al. 1999). Although the follicular growth rates recorded in this system in vitro are slightly accelerated compared with growth rates in adult animals, they closely mimic the growth rates of similar staged follicles in foetal ovaries in vivo. This extended growth phase is important as it facilitates the sequential accumulation of the payload of RNAs and proteins required to support oocyte developmental competence.

The potential of three-dimensional pre-antral follicle culture has been demonstrated in other domestic species including pigs (Wu et al. 2001); cattle (Gutierrez et al. 2000, McCaffery et al. 2000, Thomas et al. 2001, 2007) 
and humans (Picton et al. 1999b, Telfer et al. 2008). The IVG of porcine follicles has produced a small number of meiotically competent oocytes following growth in both collagen gels (Hirao et al. 1994), and in uncoated culture wells (Telfer et al. 2000). In vitro fertilisation of IVGderived porcine metaphase II oocytes resulted in limited blastocyst production (Wu et al. 2001). The IVG of human pre-antral graulosa-oocyte-complexes and whole follicles have resulted in development up to antral sizes following enzymatic isolation and culture within agar (Roy \& Treacy 1993) or collagen (Abir et al. 1999) gels. Mechanical isolation and IVG have also been demonstrated (Abir et al. 1997), although levels of atresia following culture were found to be high. In the most recent report (Telfer et al. 2008), pre-antral follicles have been isolated mechanically from cortical tissue after 6 days of culture and antral cavity formation occurred in the isolated follicles very rapidly, within 2 days of isolation. The meiotic competence and developmental capacity of human oocytes grown from pre-antral stages in vitro has yet to be confirmed.

\section{The IVM of oocytes}

The final phase in a strategy for the complete IVG of follicles is the IVM of the oocytes derived following in vitro folliculogenesis. There are already reports in the literature that clearly demonstrate the utility of IVM as a stand alone technology for assisted reproduction in may species including humans (for example, for review see van Wagtendonk-de Leeuw et al. 2000, Picton 2002, Banwell \& Thompson 2008). Oocyte maturational competence is linked to follicle size and the follicular microenvironment immediately before nuclear and cytoplasmic maturation. Just as has been recorded for IVG, there is a clear need to optimise IVM culture media (Filali et al. 2008) and to test the efficacy of physiologically relevant additives such as human chorionic gonadotrophin (Ge et al. 2008); umbilical cord blood (Zhang et al. 2007); and FCS (van Wagtendonk-de Leeuw et al. 2000); as well as to test the efficacy of physiologically relevant additives such as follicular fluid meiosis activating sterol (Gröndahl et al. 2000a, 2000b) and fetuin (Schroeder et al. 1990, Dell'Aquila et al. 1999); and to standardise factors such as priming with $\mathrm{FSH}$, time of aspiration and the time interval to maturation in vitro (Mikkelsen et al. 2000). There is evidence that meiotic maturation and fertilisation rates and blastocyst production are compromised when compared with in vivo matured counterparts (Banwell \& Thompson 2008). Furthermore, there are concerns about the safety of IVM and the genetic health of IVM oocytes (Smitz et al. 2007) and the long-term health of embryos, foetuses and neonates after IVM. The efficacy of stand alone IVM systems also appears to depend on cumulus-GC association, GC differentiation and follicle size and atresia at the time of oocyte harvest. It is likely that the requirements for IVM will become even more rigorous when applied to the maturation of the limited numbers of mature oocytes harvested following the IVG of follicles.

\section{Future prospects for the IVG and maturation of follicles}

Overall, the evidence reviewed here supports the concept that the complete IVG of follicles from large animals and human will only be achieved through the development and use of a multistage culture strategy (Fig. 5) as has previously been proposed by a number of follicle culture practitioners (for example: Eppig \& O'Brien 1996, Picton et al. 1999b). Four steps are required to facilitate the complete IVG of follicles with the production of healthy, fertile oocytes:

- Phase 1 - in situ culture of primordial and primary follicles. This step will support the initiation and maintenance of primordial and primary follicle growth to the secondary stage of development.

- Phase 2 -isolated pre-antral-antral follicle culture. This stage will support antral cavity formation and early antral growth as well as oocyte growth to full size.

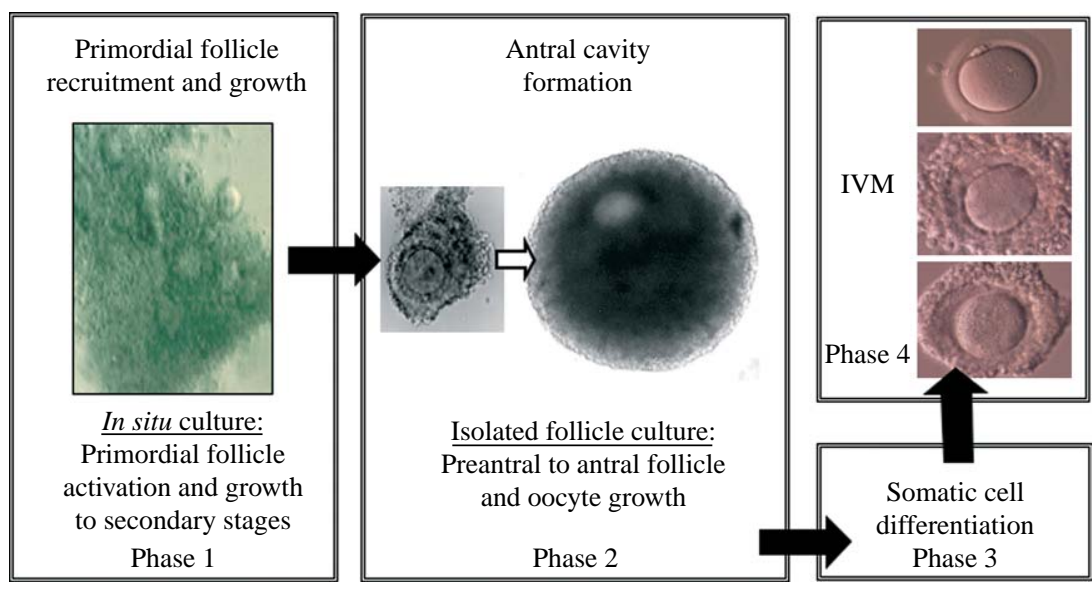

www.reproduction-online.org
Figure 5 Multi-step strategy for the complete in vitro growth and maturation of follicles from large animals and humans. The images shown are of human follicles and oocytes. 
- Phase 3 - induction of differentiated function in follicular somatic cells. Phase 3 will support the induction of steroidogenic function, especially aromatase activity and oestradiol synthesis by the GCs that are required to facilitate the acquisition of oocyte cytoplasmic competence.

- Phase 4-IVM of oocytes. The final phase of the IVG system enables the harvest and maturation of the fullygrown, cumulus enclosed, germinal vesicle staged oocytes from in vitro grown follicles and drives meiotic progression of oocytes to metaphase II before harvest and insemination.

\section{Conclusion}

Significant progress has been made in the development of improved methods for the IVG and maturation of follicles and oocytes across a range of mammalian species. The potential for the complete IVG from primordial follicles is realistic but this has only been achieved in mouse with limited efficiency and the full maturation of oocytes from species with longer developmental times for completion of oogenesis is a more formidable task. Further technological advances and optimisation of culture environments are required to improve and extend IVG and IVM culture methodologies before they can be used effectively in large animals and humans. Finally, before these strategies can be utilised therapeutically, extensive testing is required to confirm the epigenetic health and genetic normality of IVGderived oocytes before the fertility of the oocytes and developmental competence of the embryos they produce can be confirmed. Until further extensive research has been conducted the therapeutic potential of IVG and IVM technologies will not be fully realised.

\section{Declaration of interest}

The authors declare that there is no conflict of interest that could be perceived as prejudicing the impartiality of the research reported.

\section{Funding}

The authors gratefully acknowledge that Dr SE Harris is supported by a Research Grant (Reference Number BB/C007395/1) from Biotechnology and Biological Sciences Research Council. Dr EL Chambers is supported by a grant from the Candlelighters, Childrens Cancer Charity, UK.

\section{References}

Abir R, Franks S, Mobberley MA, Moore PA, Margara RA \& Winston RML 1997 Mechanical isolation and in vitro growth of preantral and small antral human follicles. Fertility and Sterility 68 682-688.
Abir R, Roizman P, Fisch B, Nitke S, Okon E, Orvieto R \& Ben Rafael Z 1999 Pilot study of isolated early human follicles cultured in collagen gels for 24 hours. Human Reproduction 14 1299-1301.

Baker TG \& Neal P 1974 Organ culture of cortical fragments and Graafian follicles from human ovaries. Journal of Anatomy 117 361-371.

Banwell KM \& Thompson JG 2008 In vitro maturation of mammalian oocytes: outcomes and consequences. Seminars in Reproductive Medicine 26 162-174.

Beaujean N, Hartshorne G, Cavilla J, Taylor J, Gardner J, Wilmut I, Meehan R \& Young L 2004 Non-conservation of mammalian preimplantation methylation dynamics. Current Biology 14 266-267.

Biggers J, Whittingham D \& Donahue R 1967 The pattern of energy metabolism in the mouse oocyte and zygote. PNAS 58567.

Blandau RJ, Warrick E \& Rumery RE 1965 In vitro cultivation of fetal mouse ovaries. Fertility and Sterility 16 705-715.

Van Blerkom J, Davis P, Mathwig V \& Alexander S 2002 Domains of highpolarised and low-polarised mitochondrial may occur in mouse and human oocytes and early embryos. Human Reproduction 17 393-406.

Boland NI \& Gosden RG 1994 Effects of epidermal growth factor on the growth and differentiation of cultured mouse ovarian follicles. Journal of Reproduction and Fertility 101 369-374.

Boland NI, Humpherson PG, Leese HJ \& Gosden RG 1993 Pattern of lactate production and steroidogenesis during growth and maturation of mouse ovarian follicles in vitro. Biology of Reproduction 48 798-806.

Borghol N, Lornage J, Blachere T, Sophie Garret A \& Lefevre A 2006 Epigenetic status of the $\mathrm{H} 10$ locus in human oocytes following in vitro maturation. Genomics 87 417-426.

Braw-Tal R \& Yossefi S 1997 Studies in vivo and in vitro on the initiation of follicle growth in the bovine ovary. Journal of Reproduction and Fertility 109 165-171.

Bukovsky A, Caudle MR, Keenan JA, Wimalasena J, Foster JS \& Van Meter SE 1995 Quantitative evaluation of the cell cycle-related retinoblastoma protein and localization of Thy-1 differentiation protein macrophages during follicular development and atresia, and in human corpora lutea. Biology of Reproduction 52 776-792.

Cain L, Chatterjee S \& Collins TJ 1995 In vitro folliculogenesis of rat preantral follicles. Endocrinology 136 3369-3377.

Campbell BK, Scaramuzzi RJ \& Webb R 1996 Induction and maintenance of oestradiol and immunoreactive inhibin production with FSH by ovine granulosa cells in serum-free media. Journal of Reproduction and Fertility 106 7-16.

Carámbula SF, Figueiredo JR, Wheeler MB, Neves JP \& Mondadori RG 1999 Effect of fetal age and method of recovery on isolation of preantral follicles from bovine ovaries. Theriogenology 52 563-571.

Carroll J, Whittingham DG \& Wood MJ 1991a Effect of gonadotrophin environment on growth and development of isolated mouse primary ovarian follicles. Journal of Reproduction and Fertility 93 71-79.

Carroll J, Whittingham DG \& Wood MJ $1991 b$ Growth in vitro and acquisition of meiotic competence after the cryopreservation of isolated mouse primary ovarian follicles. Reproduction, Fertility, and Development 3 593-599.

Cecconi S, Barboni B, Coccia M \& Mattioli M 1999 In vitro development of sheep preantral follicles. Biology of Reproduction 60 594-601.

Chang SCS, Anderson W, Lewis JC, Ryan RJ \& Kang YH 1977 The porcine ovarian follicle. II. Electron microscopic study of surface features of granulosa cells at different stages of development. Biology of Reproduction 16 349-357.

Cortvrindt R, Smitz J \& Van Steirteghem AC 1996 In vitro maturation, fertilization and embryo development of immature oocytes from early preantral follicles from prepubertal mice in a simplified culture system. Human Reproduction 11 2656-2666.

Cushman RA, Wahl CM \& Fortune JE 2002 Bovine cortical pieces grafted to chick embryonic membranes: a model for studies on the activation of primordial follicles. Human Reproduction 17 48-54.

Dell'Aquila ME, Felici MD, Massari S, Maritato F \& Minoia P 1999 Effect of fetuin on zona pellucida hardening and fertilisability of equine oocytes matured in vitro. Biology of Reproduction 61 533-540.

Devine PJ, Rajapaksa KS \& Hoyer PB 2002 In vitro ovarian tissue and organ culture: a review. Frontiers in Bioscience 7 d1979-d1989.

Diaz FJ, Wigglesworth K \& Eppig JJ 2007 Oocytes are required for the preantral granulosa cell to cumulus cell transition in mice. Developmental Biology 305 300-311. 
Dong J, Albertini D, Nishimori K, Kumar T, Lu N \& Matzuk M 1996 Growth differentiation factor-9 is required during early ovarian folliculogenesis. Nature 383 531-535.

Eppig JJ 1976 Analysis of mouse oogenesis in vitro. Oocyte isolation and the utilization of exogenous energy sources by growing oocytes. Journal of Experimental Zoology 198 375-382.

Eppig JJ 1994 Further reflections on culture systems for the growth of oocytes in vitro. Human Reproduction 9 974-976.

Eppig JJ \& O'Brien MJ 1996 Development in vitro of mouse oocytes from primordial follicles. Biology of Reproduction 54 197-207.

Eppig JJ \& Schroeder AC 1989 Capacity of mouse oocytes from preantral follicles to undergo embryogenesis and development to live young after growth, maturation, and fertilization in vitro. Biology of Reproduction 41 268-276.

Eppig JJ, O'Brien MJ, Pendola FL \& Watanabe S 1998 Factors affecting the developmental competence of mouse oocytes grown in vitro: folliclestimulating hormone and insulin. Biology of Reproduction 59 1445-1453.

Fair T, Hulshof SCJ, Hyttel P \& Greve T 1997 Oocyte ultrastructure in bovine primordial to early tertiary follicles. Anatomy and Embryology $195327-336$.

Fernandez-Gonzalez R, Moreira P, Bilbao A, Jimenez A, Perez-Crespo $M$, Ramirez MA, Rodriguez De Fonseca F, Pintado B \& Gutierrez-Adan A 2004 Long-term effect of in vitro culture of mouse embryos with serum on mRNA expression of imprinting genes, development, and behaviour. PNAS 101 5880-5885.

Figueiredo JR, Hulshof SC, Van den Hurk R, Bevers MM, Nusgens B \& Beckers JF 1993 Development of a new mechanical method for the isolation of intact preantral follicles from fetal, calf and adult bovine ovaries. Theriogenology 40 789-799.

Figueiredo JR, Hulshof SCJ, Vandenhurk R, Nusgens B, Bevers MM, Ectors FJ \& Beckers JF 1994 Preservation of oocyte and granulosa-cell morphology in bovine preantral follicles cultured in vitro. Theriogenology $\mathbf{4 1}$ 1333-1346.

Filali M, Hesters L, Franchin R, Tachdjian G, Frydman R \& Frydman N 2008 Retrospective comparison of two media for in vitro maturation of oocytes. Reproductive Biomedicine Online 16 250-256.

Fortune JE, Kito S, Wandji SA \& Srsen V 1998 Activation of bovine and baboon primordial follicles in vitro. Theriogenology 49 441-449.

Fortune JE, Cushman RA, Wahl CM \& Kito S 2000 The primordial to primary follicle transition. Molecular and Cellular Endocrinology 163 53-60.

Fulka H, Mrazek M, Tepla O \& Fulka J Jr 2004 DNA methylation pattern in human zygotes and developing embryos. Reproduction 128 703-708.

Gandolfi F, Milanesi E, Pocar P, Luciano AM, Brevini TA, Acocella F, Lauria A \& Armstrong DT 1998 Comparative analysis of calf and cow oocytes during in vitro maturation. Molecular Reproduction and Development 49 168-175.

Ge HS, Huang XF, Zhang W, Zhao JZ, Lin JJ \& Zhou W 2008 Exposure to human chorionic gonadotrophin during in vitro maturation does not improve the maturation rate and developmental potential of immature oocytes from patients with polycystic ovary syndrome. Fertility and Sterility 89 98-103.

Gosden RG \& Telfer E 1987 Scaling of follicular sizes in mammalian ovaries. Journal of Zoology 211 157-168.

Gougeon A 1996 Regulation of ovarian follicular development in primates facts and hypotheses. Endocrine Reviews 17 121-155.

Greenwald GS \& Moor RM 1989 Isolation and preliminary characterization of pig primordial follicles. Journal of Reproduction and Fertility $\mathbf{8 7}$ 561-571.

Gröndahl C, Hansen TH, Marky-Nielsen K, Ottesen JL \& Hyttel P 2000a Human oocyte maturation in vitro is stimulated by meiosis-activating sterol. Human Reproduction 15 3-10.

Gröndahl C, LessI M, Farge I, Hefele-Huartung C, Wassermann K \& Otttesen JL 2000b Meiosis activating sterol mediated resumption of meiosis in mouse oocytes in vitro is influenced by protein synthesis inhibition and cholera toxin. Biology of Reproduction 62 775-780.

Gutierrez CG, Ralph JH, Telfer EE, Wilmut I \& Webb R 2000 Growth and antrum formation of bovine preantral follicles in long-term culture in vitro. Biology of Reproduction 62 1322-1328.

Harris SE \& Picton HM 2007 Metabolism of follicles and oocytes during growth and maturation. In In-Vitro Maturation of Human Oocytes - Basic Science to Clinical Application, pp 15-36. Eds SL Tan, RC Chian \& WM Buckett. Oxon, UK: Informa Health.
Harris SE, Adriaens I, Leese HJ, Gosden RG \& Picton HM 2007 Carbohydrate metabolism by murine ovarian follicles and oocytes grown in vitro. Reproduction 134 415-424.

Harris SE, Leese HJ, Gosden RG \& Picton HM 2008 Pyruvate and oxygen consumption throughout the growth and development of murine oocytes. Molecular Reproduction and Development [in press] DOI:10.1002/mrd.20945.

Hartshorne GM 1997 In vitro culture of ovarian follicles. Reviews of Reproduction 2 94-104.

Hartshorne GM, Sargent IL \& Barlow DH 1994 Meiotic progression of mouse oocytes throughout follicle growth and ovulation in vitro. Human Reproduction 9 352-359.

Haug A, Larsen B \& Smidsrod O 1967 Studies of the sequence of uronic acid residues in alginic acid. Acta Chemica Scandinavica 21 691-704.

Hirao Y, Nagai T, Kubo M, Miyano T, Miyake M \& Kato S 1994 In vitro growth and maturation of pig oocytes. Journal of Reproduction and Fertility 100 333-339.

Hovatta O, Wright C, Krausz T, Hardy K \& Winston RML 1999 Human primordial, primary and secondary ovarian follicles in long-term culture: effect of partial isolation. Human Reproduction 14 2519-2524.

Hreinsson JG, Scott JE, Rasmussen C, Swahn ML, Hsueh AJ \& Hovatta O 2002 Growth differentiation factor-9 promotes the growth, development and survival of human ovarian follicles in organ culture. Journal of Clinical Endocrinology and Metabolism 87 316-321.

Hu Y, Betzendahl I, Cortvrindt R, Smitz J \& Eichenlaub-Ritter U 2001 Effects of low $\mathrm{O}_{2}$ and ageing on spindles and chromosomes in mouse oocytes from pre-antral follicle culture. Human Reproduction $\mathbf{1 6}$ 737-748.

Hulshof SCJ, Figueiredo JR, Beckers JF, Bevers MM, Vanderdonk JA \& Vandenhurk R 1995 Effects of fetal bovine serum, FSH and 17- $\beta$-estradiol on the culture of bovine preantral follicles. Theriogenology 44 217-226.

Hulshof SCJ, Figueiredo JR, Beckers JF, Bevers MM, Vanderstichele H \& van den Hurk R 1997 Bovine preantral follicles and activin: immunohistochemistry for activin and activin receptor and the effect of bovine activin A in vitro. Theriogenology 48 133-142.

Huntriss J \& Picton HM 2008 Epigenetic consequences of assisted reproduction and infertility on the human preimplantation embryo. Human Fertility 11 85-94.

Huntriss J, Gosden R, Hinkins M, Oliver B, Miller D, Rutherford A \& Picton H 2002 Isolation, characterisation, and expression of the human factor in the germline alpha (FIGLA) in ovarian follicles and oocytes. Molecular Human Reproduction 8 1087-1095.

Van den Hurh R, Abir R, Telfer EE \& Bevers MM 2000 Primate and bovine immature oocytes and follicles as sources of fertilizable oocytes. Human Reproduction Update 6 457-474.

Imamura T, Kerjean A, Heams T, Kupiec JJ, Thenevin C \& Pàldi A 2005 Dynamic CpG and non-CpG methylation of the Peg1/Mest gene in the mouse oocyte and preimplantation embryo. Journal of Biological Chemistry $28020171-20175$.

Itoh T \& Hoshi H 2000 Efficient isolation and long-term viability of bovine small preantral follicles in vitro. In Vitro Cellular \& Developmental Biology. Animal 36 235-240.

Jewgenow K 1998 Role of media, protein and energy supplements on maintenance of morphology and DNA-synthesis of small preantral domestic cat follicles during short-term culture. Theriogenology $\mathbf{4 9}$ $1567-1577$.

Jin P, Harris SE \& Picton HM 2004 The effect of ascorbic acid on ovine preantral follicle development in vitro. Proceedings of the Society for Reproduction and Fertility, 2004 Annual Conference, Ghent, Belgium. P22.

Jin P, Harris SE \& Picton HM 2007 Effect of oxygen tension on ovine follicle growth in vitro. Fertility 2007 P35.

Kerjean A, Couvert P, Heams T, Chalas C, Poirier K, Chelly J, Jouannet $P$, Paldi A \& Poirot C 2003 In vitro follicular growth affects oocyte imprinting establishment in mice. European Journal of Human Genetics 11 493-496.

Khosla S, Dean W, Brown D, Reik W \& Feil R 2001 Culture of preimplantation mouse embryos affects fetal development and the expression of imprinted genes. Biology of Reproduction 64 918-926.

Knight PG \& Glister C 2006 TGF- $\beta$ superfamily members and ovarian follicle development. Reproduction 132 191-206. 
Kotsuji F, Kubo M \& Tominaga A 1994 Effect of interactions between granulosa and theca cells on meiotic arrest in bovine oocytes. Journal of Reproduction and Fertility 100 151-156.

Kreeger PK, Deck JW, Woodruff TK \& Shea LD 2007 The in vitro regulation of ovarian follicle development using alginate-extracellular matrix gels. Biomaterials 27 714-723.

Lane M \& Gardner DK 2003 Ammonium induces aberrant blastocyst differentiation, metabolism, $\mathrm{pH}$ regulation, gene expression and subsequently alters fetal development in the mouse. Biology of Reproduction 69 1109-1117.

Leese HJ \& Barton AM 1984 Pyruvate and glucose uptake by mouse ova and preimplantation embryos. Journal of Reproduction and Fertility 72 9-13.

Liu J, van der Elst J, van den Broecke R \& Dhont M 2001 Live offspring by in vitro fertilization of oocytes from cryopreserved primordial mouse follicles after sequential in vivo transplantation and in vivo maturation. Biology of Reproduction 64 171-178.

Louhio H, Hovatta O, Sjöberg J \& Tuuri T 2000 The effects of insulin, and insulin-like growth factors I and II on human ovarian follicles in longterm culture. Molecular Human Reproduction 6 694-698.

Lucci CM, Kacinskis MA, Rumpf R \& Báo SN 2004 Effects of lowered temperatures and media on short-term preservation of zebu (Bos indicus) preantral ovarian follicles. Theriogenology 61 461-472.

McCaffery FH, Leask R, Riley SC \& Telfer EE 2000 Culture of bovine preantral follicles in a serum-free system: markers for assessment of growth and development. Biology of Reproduction 63 267-273.

McGrath SA, Esquela AF \& Lee S-J 1995 Oocyte-specific expression of growth/differentiation factor-9. Molecular Endocrinology 9 131-136.

McNatty KP, Heath DA, Lundy T, Fidler AE, Quirke L, O'Connell A, Smith P, Groome N \& Tisdall DJ 1999 Control of early ovarian follicular development. Journal of Reproduction and Fertility 49 123-135.

McNatty KP, Reader K, Smith P, Heath DA \& Juengel JL 2007 Control of ovarian follicular development to the gonadotrophin-dependent phase: a 2006 perspective. Society of Reproduction and Fertility 64 55-68.

Mehlmann LM 2005 Oocyte-specific expression of Gpr3 is required for the maintenance of meiotic arrest in mouse oocytes. Developmental Biology 288 397-404.

Mikkelsen AL, Smith S \& Lindenberg S 2000 Possible factors affecting the development of oocytes in in vitro maturation. Human Reproduction 15 11-17.

Morison IM, Ramsay JP \& Spencer HG 2005 A census of mammalian imprinting. Trends in Genetics 21 457-465.

Muruvi W, Picton HM, Rodway RG \& Joyce IM 2005 In vitro growth of oocytes from primordial follicles isolated from frozen-thawed lamb ovaries. Theriogenology 64 1357-1370.

Muruvi W, Picton HM, Rodway RG \& Joyce IM 2008 In vitro growth and differentiation of primary follicles isolated from cryopreserved sheep ovarian tissue. Animal Reproduction Science [in press] DOI:10.1016/j.anireprosci.2008.04.001.

Nayudu PL \& Osborn SM 1992 Factors influencing the rate of preantral and antral growth of mouse ovarian follicles in vitro. Journal of Reproduction and Fertility 95 349-362.

Nayudu PL, Fehrenbach A, Kiesel P, Vitt UA, Pancharatna K \& Osborn SM 2001 Progress towards understanding follicle development in vitro: appearances are not deceiving. Archives of Medical Research 32 587-594.

Newton H \& Illingworth P 2001 In vitro growth of murine preantral follicles after isolation from cryopreserved ovarian tissue. Human Reproduction 16 423-429.

Newton H, Picton HM \& Gosden RG 1999 In vitro growth of oocytegranulosa cell complexes isolated from cryopreserved ovine tissue. Journal of Reproduction and Fertility 115 141-150.

Nuttinck F, Mermillod P, Massip A \& Dessy F 1993 Characterization of in vitro growth of bovine preantral ovarian follicles - a preliminary study. Theriogenology 39 811-821.

Obata Y, Kono T \& Hatada I 2002 Maturation of mouse fetal germ cells in vitro. Nature 418 497-498.

Oktay K, Briggs D \& Gosden RG 1997 Ontogeny of follicle stimulating hormone receptor gene expression in isolated human ovarian follicles. Journal of Clinical Endocrinology and Metabolism 82 3748-3751.

Osborn SM, Gook DA, Stern K \& Speirs AL 1997 The isolation and culture of human primordial follicles from fresh ovarian tissue. Human Reproduction 12 (Supplement 1) 153.
Otsuka F, Moore RK, Iemura S, Ueno N \& Shimasaki S 2001 Follistatin inhibits the function of the oocyte-derived factor BMP-15. Biochemical and Biophysical Research Communications 289 961-966.

Pan H, O'Brien MJ, Wigglesworth K, Eppig JJ \& Schultz RM 2005 Transcript profiling during mouse oocyte development and the effect of gonadotrophin priming and development in vitro. Developmental Biology 286 493-506.

Pangas SA, Saudye H, Shea LD \& Woodruff TH 2003 Novel approaches for three-dimensional culture of granulosa cell-oocyte complexes. Tissue Engineering 9 1013-1021.

Pesty A, Miyara F, Debey P, Lefevre B \& Poirot C 2007 Multiparameter assessment of mouse oogenesis during follicular growth in vitro. Molecular Human Reproduction 13 3-9.

Peters H, Byskov AG, Himelstein-Braw R \& Faber M 1975 Follicular growth: the basic event in the mouse and human ovary. Journal of Reproduction and Fertility 45 559-566.

Picton HM 2001 Activation of follicle development: the primordial follicle. Theriogenology 55 1193-1210.

Picton HM 2002 Oocyte maturation in vitro. Current Opinion in Obstetrics and Gynecology 14 295-302.

Picton HM, Campbell BK \& Hunter MG 1999a Maintenance of oestradiol production and cytochrome P450 aromatase enzyme messenger ribonucleic acid expression in long-term serum-free cultures of porcine granulosa cells. Journal of Reproduction and Fertility 115 67-77.

Picton HM, Mkandla A, Salha O, Wynn P \& Gosden RG $1999 \mathrm{~b}$ Initiation of human primordial follicle growth in vitro in ultra-thin slices of ovarian cortex. Human Reproduction 14 (Abstract book 1) 11 (abstract 0-020).

Picton HM, Kim S \& Gosden RG 2000 Cryopreservation of gonadal tissue and cells. British Medical Bulletin 56 603-615.

Picton HM, Danfour M, Harris SE, Chambers E \& Huntriss J 2003 In vitro growth and maturation of oocyte. Reproduction Supplement 61 445-462.

Picton HM, Harris SE \& Chambers EL 2004 Prospects for follicle culture. In Preservation of Fertility, pp 191-207. Eds T Tulandi \& RG Gosden. London: Taylor and Francis Group.

Picton HM, Muruvi W \& Jin P 2007 Interaction of oocyte and somatic cells. In In-Vitro Maturation of Human Oocytes - Basic Science to Clinical Application, pp 37-48. Eds SL Tan, RC Chian \& WM Buckett. Oxon, UK: Informa Health.

Qu J, Godin PA, Nisolle M \& Donnez J 2000 Distribution and epidermal growth factor receptor expression of primordial follicles in human ovarian tissue before and after cryopreservation. Human Reproduction 15 302-310.

Qureshi A, Nussey S, Bano G, Musonda P, Whitehead S \& Mason H 2008 Testosterone selectively increases primary follicles in ovarian cortex grafted onto embryonic chick membranes: relevance to polycystic ovaries. Reproduction 136 187-194.

Rice S, Ojha K \& Mason H 2008 Human ovarian biopsies as a viable source of pre-antral follicles. Human Reproduction 23 600-605.

Richard FJ \& Sirard MA 1996 Effects of follicular cells on oocyte maturation. II. Theca cell inhibition of bovine oocyte maturation in vitro. Biology of Reproduction 54 22-28.

Roberts R, Franks S \& Hardy K 2002 Culture environment modulates maturation and metabolism of human oocytes. Human Reproduction $\mathbf{1 7}$ 2950-2956.

Rose UM, Hanssen RG \& Kloosterboer HJ 1999 Development and characterisation of an in vitro ovulation model using mouse ovarian follicles. Biology of Reproduction 61 503-511.

Rowghani NM, Heise MK, McKeel D, McGee EA, Koepsel RR \& Russel AJ 2004 Maintenance of morphology and growth of ovarian follicles in suspension culture. Tissue Engineering 10 545-552.

Roy SK \& Treacy BJ 1993 Isolation and long-term culture of human preantral follicles. Fertility and Sterility 59 783-790.

Sagirkaya H, Misirlioglu M, Kaya A, First NL, Parrish JJ \& Memili E 2007 Developmental potential of bovine oocytes cultured in different maturation and culture conditions. Animal Reproduction Science 101 225-240.

Saha S, Shimizu M, Geshi M \& Izaike Y 2000 In vitro culture of bovine preantral follicles. Animal Reproduction Science 63 27-39. 
Schmidt KL, Ernst E, Byskov AG, Nyboe Anderson A \& Yding Anderson C 2003 Survival of primordial follicles following prolonged transportation of ovarian tissue prior to cryopreservation. Human Reproduction $\mathbf{1 8}$ 2654-2659.

Schoenfelder M \& Einspanier R 2003 Expression of hyaluronan synthases and corresponding hyaluronan receptors is differentially regulated during oocyte maturation in cattle. Biology of Reproduction 69 269-277.

Schroeder AC, Schultz RM, Kopf GS, Tayler FR, Becker RB \& Eppig JJ 1990 Fetuin inhibits zona pellucida and conversion of ZP2 to ZP2f during spontaneous mouse oocyte maturation in vitro in the absence of serum. Biology of Reproduction 43 891-897.

Scott JE, Carlsson IB, Bavister BD \& Hovatta O 2004a Human ovarian tissue cultures: extracellular matrix composition, coating density and tissue dimensions. Reproductive Biomedicine Online 9 287-293.

Scott JE, Zhang P \& Hovatta O 2004b Benefits of 8-bromo-guanosine 3', 5' cyclic monophosphate (8-br-cGMP) in human ovarian cortical tissue culture. Reproductive Biomedicine Online 8 319-324.

Sela-Abramovich S, Edry I, Galiani D, Nevo N \& Dekel N 2006 Disruption of gap junctional communication within the ovarian follicle induces oocyte maturation. Endocrinology 147 2280-2286.

Shikone T, Yamoto M \& Nakano R 1992 Follicle-stimulating hormone induces functional receptors for basic fibroblast growth factor in rat granulosa cells. Endocrinology 131 1063-1068.

Shimasaki S, Zachow RJ, Li D, Kim H, lemura S-I, Ueno N, Sampath K, Chang RJ \& Erickson GF 1999 A functional bone morphogenic protein system in the ovary. PNAS 96 7282-7287.

Shuttleworth G, Broughton Pipkin F \& Hunter MG 2002 In vitro development of pig preantral follicles cultured in a serum-free medium and the effect of angiotensin II. Reproduction 123 807-818.

Smitz J \& Cortvrindt R 1998 Follicle culture after ovarian cryostorage. Maturitas 30 171-179.

Smitz J, Picton HM, Platteau P, Rutherford A, Cortvrindt R, Clyde J, Nogueira D, Devroey P, Lyby K \& Gröndahl C 2007 Principal findings from a multicenter trial investigating the safety of follicular-fluid meiosisactivating sterol for in vitro maturation of human cumulus-enclosed oocytes. Fertility and Sterility $\mathbf{8 7}$ 949-964.

Spears N, Boland NI, Murray AA \& Gosden RG 1994 Mouse oocytes derived from in vitro grown primary ovarian follicles are fertile. Human Reproduction 9 527-532.

Swain JE \& Smith GD 2007 Mechanism of oocyte maturation. In In-Vitro Maturation of Human Oocytes - Basic Science to Clinical Application, pp 83-101. Eds SL Tan, RC Chian \& WM Buckett. Oxon, UK: Informa Health.

Telfer EE 1996 The development of methods for isolation and culture of preantral follicles from bovine and porcine ovaries. Theriogenology 45 101-110.

Telfer EE, Binnie JP, McCaffery FH \& Campbell BK 2000 In vitro development of oocytes from porcine and bovine primary follicles. Molecular and Cellular Endocrinology 163 117-123.

Telfer EE, McLaughlin M, Ding C \& Thong KJ 2008 A two-step serum-free culture system supports development of human oocytes from primordial follicles in the presence of activin. Human Reproduction 23 $1151-1158$.

Thomas FH \& Vanderhyden BC 2007 Oocyte growth and developmental competence. In In-Vitro Maturation of Human Oocytes - Basic Science to Clinical Application, pp 1-15. Eds SL Tan, RC Chian \& WM Buckett. Oxon, UK: Informa Health.

Thomas FH, Leask R, Srsen V, Riley SC, Spears N \& Telfer EE 2001 Effect of ascorbic acid on health and morphology of bovine preantral follicles during long-term culture. Reproduction 122 487-495.

Thomas FH, Walters KA \& Telfer EE 2003 How to make a good oocytes: an update on in vitro models to study follicle regulation. Human Reproduction Update 9 541-555.

Thomas FH, Campbell BK, Armstrong DG \& Telfer EE 2007 Effects of IGF-I bioavailability on bovine preantral follicular development in vitro. Reproduction 133 1121-1128.

Vaccari S, Horner K, Mehlmann LM \& Conti M 2008 Generation of mouse oocytes defective in cAMP synthesis and degradation: endogenous cyclic AMP is essential for meiotic arrest. Developmental Biology 316 124-134.
Vassena R, Dee Schramm R \& Latham KE 2005 Species-dependent expression patterns of DNA methyltransferase genes in mammalian oocytes and preimplantation embryos. Molecular Reproduction and Development 72 430-436.

van Wagtendonk-de Leeuw AM, Mullaart E, de Roos APW, Merton JS, den Daas JHG, Kemp B \& de Ruigh L 2000 Effects of different reproductive techniques: AI, MOET or IVP on health and welfare of bovine offspring. Theriogenology 53 575-597.

Wandji S-A, Srsen V, Voss AK, Eppig JJ \& Fortune JE 1996 Initiation in vitro of growth of bovine primordial follicles. Biology of Reproduction $\mathbf{5 5}$ 942-948.

Wandji SA, Srsen V, Nathanielsz PW, Eppig JJ \& Fortune JE 1997 Initiation of growth of baboon primordial follicles in vitro. Human Reproduction 12 1993-2001.

Webb R \& Campbell BK 2007 Development of the dominant follicle: mechanisms of selection and maintenance of oocyte quality. Society of Reproduction and Fertility 64 141-163.

Webber LJ, Stubbs SA, Stark J, Margara RA, Trew GH, Lavery SA, Hardy K \& Franks S 2007 Prolonged survival in culture of preantral follicles from polycystic ovaries. Journal of Clinical Endocrinology and Metabolism 92 1975-1978.

West ER, Xu M, Woodruff TK \& Shea LD 2007 Physical properties of alginate hydrogels and their effects on in vitro follicle development. Biomaterials 28 4439-4448.

Wilding M, Dale B, Marino M, di Matteo L, Alviggi C, Pisaturo ML, Lombardi L \& De Placido G 2001 Mitochondrial aggregation patterns and activity in human oocytes and preimplantation embryos. Human Reproduction 16 909-917.

Wright C, Hovatta O, Margara R, Trowe G, Winston RML, Franks S \& Hardy K 1999 Effect of follicle stimulating hormone and serum substitution on the development and growth of early human follicles. Human Reproduction 14 1555-1562.

Wu J, Emery BR \& Carrell DT 2001 In vitro growth, maturation, fertilization, and embryonic development of oocytes from porcine preantral follicles. Biology of Reproduction 64 375-381.

Wycherley G, Downey D, Kane MT \& Hynes AC 2004 A novel follicle culture system markedly increases follicle volume and growth of ovarian follicles in suspension culture. Reproduction 127 669-677.

Xu M, West E, Shea LD \& Woodruff TK 2006 Identification of a stage specific permissive in vitro culture environment for follicle growth and oocyte development. Biology of Reproduction 75 916-923.

Ye J, Coleman J, Hunter MG, Craigon J, Campbell KH \& Luck MR 2007 Physiological temperature variants and culture media modify meiotic progression and developmental potential of pig oocytes in vitro. Reproduction 133 877-886.

Young LE, Sinclaire KD \& Wilmut I 1998 Large offspring syndrome in cattle and sheep. Reviews of Reproduction 3 155-163.

Yu N \& Roy SK 1999 Development of primordial and prenatal follicles from undifferentiated somatic cells and oocytes in the hamster prenatal ovary in vitro: effect of insulin. Biology of Reproduction 61 1558-1567.

Zhang P, Louhio H, Tuuri T, Sjöberg J, Hreinsson J, Telfer EE \& Hovatta $\mathbf{O}$ 2004 In vitro effect of cyclic adenosine 3',5'-monophosphate (cAMP) on early human ovarian follicles. Journal of Assisted Reproduction and Genetics 21 310-306.

Zhang ZG, Zhao JH, Wei ZL, Cong L, Zhou P \& Cao YX 2007 Human umbilical cord blood serum in culture medium on oocyte maturation in vitro. Archives of Andrology 53 303-307.

Zhao J, Dorland M, Taverne MA, Van Der Weijden GC, Bevers MM \& Van Den Hurk R 2000 In vitro culture of rat pre-antral follicles with emphasis on follicular interactions. Molecular Reproduction and Development 55 $65-74$.

Received 5 July 2008

First decision 4 August 2008

Revised manuscript received 15 September 2008

Accepted 7 October 2008 